\title{
PATRONATO RURAL, RELAÇÕES DE PARENTESCO E REPRESENTAÇÃO POLÍTICA (PRIMEIRAS ANOTAÇÕES)
}

\author{
Regina Bruno ${ }^{1}$ \\ Afonso Fernandes ${ }^{2}$ \\ Felipe Prado $^{3}$
}

\begin{abstract}
Resumo: Vários estudos sobre o patronato rural no Brasil ressaltam a importância da família e das relações de parentesco na representação política e corporativa de grandes proprietários de terra e empresários rurais e do agronegócio, ainda que não tenham esta questão como seu objeto central. Neste sentido, numa primeira aproximação ao problema, o objetivo do artigo é refletir sobre o papel da família na construção da representação política do patronato rural no Brasil. Tendo como referência empírica Roberto Rodrigues e Katia Abreu - dois principais expoentes da atual geração de representantes do patronato rural e do agronegócio - interessa-nos entender como as classes dominantes agrárias brasileiras concebem e recorrem à família e às relações de parentesco na construção e reprodução do poder político. De uma perspectiva mais geral, três aspectos são definidores da dinâmica das relações familiares do patronato rural e orientam a representação política e corporativa dos grandes proprietários de terra e empresários rurais e do agronegócio no Brasil: i- a força dos clãs familiares na política, ii- o entrelaçamento de práticas consideradas modernas e atrasadas e iii- um conservadorismo arraigado. Como veremos, enquanto Rodrigues defende uma concepção de família como unidade administrativa de gestão profissional dos negócios, Katia Abreu ressalta os valores da tradição familiar como principal traço da política. Assim, pudemos constatar que, mesmo com significativas diferenças, ambos recorrem à instituição família como ferramenta de construção da sua representação política e forma de reprodução social, encontrando nas relações familiares fontes fundamentais de legitimidade política e social.
\end{abstract}

Palavras-chave: Patronato Rural, Família, Representação Política

\section{RURAL PATRONAGE, RELATIONSHIPS OF RELATIONSHIPS AND POLITICAL REPRESENTATION (FIRST NOTES)}

\begin{abstract}
Several studies on rural patronage in Brazil emphasize the importance of family and kinship relations in the political and corporate representation of large landowners and rural entrepreneurs and agribusiness, although they do not have this question as their central object. In this sense, in a first approach to the problem, the objective of the article is to reflect on the role of the family in the construction of the political representation of rural patronage in Brazil. Having as empirical reference Roberto Rodrigues and Katia Abreu - two main exponents of the current generation of representatives of rural patronage and agribusiness - we are interested in understanding how the Brazilian agrarian dominant classes conceive and resort to family and kinship relations in the construction and reproduction of the political power. From a more general perspective, three aspects are defining the dynamics of family relations of the rural patronage and guide the political and corporate representation of the great landowners and rural entrepreneurs and agribusiness in Brazil: $\mathrm{i}$ - the strength of family clans in politics, ii - the interweaving of practices considered modern and backward and iii- a deep-rooted conservatism. As we shall see, while Rodrigues defends a conception of family as an administrative unit of professional business management, Katia Abreu emphasizes the values of family tradition as the main feature of politics. Thus, we could verify that, even with significant differences, both resort to the family institution as a tool to build their political representation and social reproduction, finding in family relationships fundamental sources of political and social legitimacy.
\end{abstract}

Key words: Rural Patronage, Family, Political Representation

- Enviado em 15/07/2017

- Aprovado em 28/07/2017

1 Professora do CPDA/UFRRJ. Coordenadora do Núcleo de Estudo e Pesquisa sobre Ruralismo, Agronegócio e Relações de Poder (NARUP).

${ }^{2}$ Mestrando do CPDA/UFRRJ e integrante do NARUP. Email: afonsomenezes@gmail.com

${ }^{3}$ Doutorando do CPDA/UFRRJ e integrante do NARUP. Email: pradosfellipe@gmail.com

Uma versão preliminar desse texto foi apresentada no $18^{\circ}$ Congresso Brasileiro de Sociologia. Que Sociologia fazemos? Interfaces com contextos locais, nacionais e globais realizado de 26 a 29 de julho de 2017 no Centro de Convenções Ulysses Guimarães, Brasília/DF. 


\section{Introdução}

Vários estudos sobre o patronato rural no Brasil ressaltam a importância da família e das relações de parentesco na representação política e corporativa de grandes proprietários de terra e empresários rurais e do agronegócio, embora não se constituam em objeto de estudo em si e apontam relações que reafirmam o espírito coletivo, a solidariedade e a lealdade, apesar das tensões existentes, como diria Pierre Bourdieu (2011) ao discorrer sobre o espírito da família.

O objetivo do artigo é refletir sobre o papel da família na construção da representação política do patronato rural no Brasil. Tendo como referência empírica Roberto Rodrigues e Katia Abreu - dois principais expoentes da atual geração de representantes do patronato rural e do agronegócio - interessa-nos entender como as classes dominantes agrárias brasileiras concebem e recorrem à família e as relações de parentesco na construção e reprodução do poder político. Ou seja, pensar a família como espaço privilegiado de intensificação dos laços sociais que os une reciprocamente na defesa de seus interesses, na reafirmação de valores e na construção de projetos de vida. Como veremos, enquanto Rodrigues defende uma concepção de família como unidade administrativa de gestão profissional dos negócios, Katia Abreu ressalta os valores da tradição familiar como principal traço da política.

De uma perspectiva mais geral, três aspectos são definidores na dinâmica das relações familiares do patronato rural e orientam a representação política e corporativa dos grandes proprietários de terra e empresários rurais e do agronegócio no Brasil: i- a força dos clãs familiares na política, ii- o entrelaçamento de práticas consideradas modernas e atrasadas e iii- um conservadorismo arraigado. São traços que se complementam e se alimentam mutuamente.

O perfil dominante é o clã familiar. São pessoas unidas por algum grau de parentesco, amiúde definidas pela descendência de um ancestral comum e de uma linhagem predominantemente masculina, legitimadoras dos privilégios, das desigualdades e das relações de poder. Em nossas pesquisas nos anos recentes sobre organização e representação política destacam-se os clãs Caiado, os Junqueira Junior, os Piciani, dentre tantos outros ${ }^{4}$. Dessa perspectiva temos a primazia da família enquanto espaço social fundamental do indivíduo, a autoridade do chefe familiar, a crença na

\footnotetext{
${ }^{4}$ Tal perfil não se restringe aos grupos patronais rurais e agroindustriais. Durante a Nova República o empresário Ricardo Semler - um dos idealizadores do Pensamento Nacional das Bases Empresariais (PNBE) -, já questionava esse aspecto e criticava a presença de membros familiares na direção das empresas e na direção instancias de representação de classe considerado um entrave à modernização empresarial.
} 
santidade da tradição e dos poderes patriarcais (Weber) e a "lei do patrão" sobrepondo-se ou confundindo-se com a lei da nação.

Uma segunda característica consiste no entrelaçamento de práticas e de concepções consideradas modernas e arcaicas. É a ambivalência e funciona como princípio ordenador de uma identidade patronal rural e de uma mesma visão de mundo: o mesmo grupo que se orienta por parâmetros de competitividade e de rentabilidade empresarial reproduzir o improdutividade. Por sua vez, a defesa da livre iniciativa e do fortalecimento do mercado convive com a exigência de um Estado "provedor" e "protetor" do patronato rural. No plano das relações de trabalho, a ambivalência se manifesta no reconhecimento dos direitos e da carteira assinada para os trabalhadores rurais ao mesmo tempo em que se recorre trabalho escravo. No campo dos direitos, as políticas de responsabilidade social convivem com as milícias, as listas dos marcados para morrer e o recurso à violência como prática de classe.

E por fim, como terceiro traço, temos o conservadorismo. Grandes proprietários de terra e empresários do agronegócio não avessos à tecnologia, mas aos direitos sociais. Para o pensamento conservador o "igualitarismo" é socialmente nefasto porque atomiza a sociedade e destrói as elites diz Mannheim (1981). Um conservadorismo que dá o suporte ao discurso patronal em defesa da punição e da humilhação como recurso de poder, a dificuldade de separar a coisa pública do bem privado, uma concepção de propriedade da terra como direito absoluto e que não consegue se desvencilhar dos valores ligados ao patrimonialismo e ao clientelismo.

\section{A família Rodrigues e a valorização da gestão}

Roberto Rodrigues tem origem numa família de imigrantes italianos que se assentaram em São Paulo na região de Piracicaba e Tietê para plantar café no início do século XX. Sofrendo com a crise de 1929 a família teve de vender suas terras e Antonio José Rodrigues, seu pai, migrou para a região de Ribeirão Preto (SP), mais precisamente no município de Jaboticabal, para trabalhar como técnico na produção de cana, dando início a uma bem sucedida trajetória como produtor rural e liderança política classista e institucional no estado de São Paulo. Dessa maneira, Roberto Rodrigues, se formou na convivência com os negócios do pai, sua atividade política e com seus estudos, cursando a mesma graduação que seu pai - Agronomia na Escola Superior de Agricultura Luís de Queiroz, na Universidade de São Paulo (ESALQ/USP). Trilhando os passos familiares, Roberto Rodrigues se constituiu numa das mais expressivas lideranças classistas do patronato rural 
das últimas décadas, galgando a posição de presidente da Organização das Cooperativas Brasileiras (OCB) e sendo um reconhecido articulador da Associação Brasileira de Agribusiness (ABAG).

No caso dos Rodrigues, eles reivindicam uma filosofia de gestão dos negócios própria. Uma filosofia evidencia três aspectos de distinção da família na reprodução seu poder político e econômico: i-a valorização da formação acadêmica, no caso em engenharia agronômica na ESALQ (pai, mãe, filhos, avô); ii- o investimento em inovação tecnológica nos empreendimentos da família e iii- a atuação política classista no movimento cooperativista e na construção da representação política do que veio a ficar conhecido como agronegócio. São traços sugerem uma concepção de família como unidade administrativa de gestão profissional dos negócios.

No entanto, apesar de conferir às relações familiares um lugar de destaque, como empresa moderna, podemos observar traços tradicionais, onde os filhos homens e primogênitos parecem assumir o protagonismo da gestão administrativa e da representação política e em que a divisão das atribuições se transmite internamente, entre os entes familiares e suas gerações

A presença de uma "filosofia de gestão", ao aparecer em destaque na narrativa da trajetória familiar, expressa com relativa clareza a associação entre os negócios e a família. Assim, a família ocupa o lugar de unidade administrativa que segue determinados padrões de gestão e profissionalização, fazendo com que Paulo Rodrigues defina os princípios familiares na produção agrícola da seguinte maneira:

\begin{abstract}
A nossa filosofia está baseada em um tripé bastante sólido que hoje acabou sendo chamado de sustentabilidade, mas que nós temos documentos escritos da década de 50 [risos] que remetem a esse aspecto. Esse tripé nada mais é do que tecnologia agrícola, que de certa forma, é o lado econômico do processo. Quer dizer, em agronomia, em agricultura a tecnologia agrícola é o que garante resultado. O segundo aspecto era a valorização do homem, através da criação de oportunidades, o desenvolvimento das pessoas propriamente. E o terceiro era a questão ambiental. Quer dizer, ter uma relação com o ambiente que fosse sempre positiva no sentido de manter a produção sempre crescente. Então esse tripé de sustentação, por onde passam todas as nossas decisões, na verdade começou lá atrás na década de $50 \mathrm{com}$ meu avô. E a gente deu sequência nesse processo. ${ }^{5}$
\end{abstract}

Neste sentido, podemos observar os dois primeiros aspectos da forma como a família e as relações de parentesco aparecem na fala do filho primogênito de Roberto Rodrigues: a busca familiar por estar sempre na vanguarda produtiva e tecnológica da agricultura e a noção de "valorização" e "oportunidades" como referenciais para o acesso ao conhecimento técnico, muito visível na íntima e histórica relação da família com a ESALQ/USP. Adicionando-se aos dois primeiros referenciais, Paulo Rodrigues ainda agrega a preocupação com a questão ambiental sob

\footnotetext{
${ }^{5}$ Entrevista Paulo Rodrigues http://cpdoc.fgv.br/agronegocio/paulo-rodrigues. Acesso 23.julho.2017.
} 
uma ótica técnica e moderna que reconhece o tema como questão e busca apontar respostas que não signifiquem a limitação dos índices de produtividade.

O terceiro aspecto ressaltado por nós é a dimensão da militância política classista que, embora não apareça como um dos três pilares da filosofia pregada por Paulo Rodrigues está indiscutivelmente presente na trajetória individual e coletiva da família Rodrigues. Antonio Rodrigues teve uma larga trajetória política que se verificou tanto no associativismo civil quanto em postos diversos e estratégicos no interior do Estado restrito. Especialmente após transferir as funções administrativas da Fazenda ao seu filho, Roberto Rodrigues, Antonio Rodrigues intensificou sua militância política saindo de líder sindical regional e vereador a Secretário de Estado da Agricultura, Vice-Governador de São Paulo e fundador da OCB. No mesmo caminho, Roberto inicia sua militância no movimento estudantil da ESALQ e dá prosseguimento a sua trajetória política no movimento cooperativista onde herdou do pai uma entidade nacional unificada na sigla da OCB, tornando-se seu grande expoente a partir de 1985, quando se tornou seu presidente e despontou na cena nacional como representante da nova geração do patronato agroindustrial brasileiro, gestados pela modernização agrícola. No caso de Paulo, embora este se encontre mais focado na direção dos negócios da família, da mesma maneira que seu pai e avô, ele ocupa postos no associativismo civil, com cargos de direção na ABAG - Ribeirão Preto (SP) e no Sindicado dos Plantadores de Cana da Região de Guariba (SP), onde a família produz.

Deste modo, os Rodrigues se apresentam como representantes de uma agricultura regida pela valorização da racionalidade empresarial, profissionalizada, científica, de vanguarda tecnológica e sensível à sua responsabilidade sócio-ambiental. No entanto, analisando outros aspectos da Família Rodrigues e de sua trajetória também é possível perceber a reprodução de habitus tradicionalista de família, onde aspectos sobre as fronteiras da formalidade nas relações familiares, os critérios políticos, econômicos e administrativos de hereditariedade, a valorização de uma história familiar e a reivindicação da condição de "agricultores familiares" se apresentam como os contrapontos que nos permitem pensar em uma visão sobre família do patronato rural carregadas de ambivalências entre o moderno e o tradicional.

As transições geracionais da Família demonstram com relativa nitidez a ambivalência a que nos referimos quando Paulo Rodrigues apresenta a forma com que Roberto, mesmo mais dedicado à "vida pública", se relaciona com a gestão dos negócios. Paulo afirma assim que seu pai ocupa uma espécie de presidência informal do conselho de administração em razão da natureza familiar do negócio. Roberto Rodrigues, por sua vez, ao tratar desta questão, ressalta que apesar de já ter transferido os negócios aos seus herdeiros, as relações familiares nos negócios se dão de forma 
profissional: "Todos têm formação e conhecimento técnico para o trabalho que desenvolvem (...). Hoje dou consultoria estratégica e recebo para isso"6. Ou seja, enquanto o primeiro ressalta a informalidade das relações justamente pela natureza familiar, Roberto, mais atento politicamente em sua fala, ressalta o profissionalismo que marca as relações familiares quando o assunto são os negócios.

Outro elemento que demonstra a divisão patrimonial da família é o relato de Paulo acerca da divisão legal de bens entre os diferentes entes familiares. Assim, nos anos 1990 o avô "fez um ajuste societário e dividiu o que era de um e o que era de outro. E aí os filhos, cada um ficou com o seu pedaço do negócio.” Atualmente somente Paulo está na atividade produtiva, mas foi igualmente realizado um acordo comum sobre a partilha patrimonial da família com a instituição de um conselho de sócios em que participam Roberto e seus quatro filhos.

No que se refere ao histórico familiar é possível observar através da fala de Roberto Rodrigues que, ao ser indagado se pertence a uma "família de fazendeiros", responde afirmativamente resumindo a trajetória dos Rodrigues na sua relação com a agricultura e a agronomia, recorrendo a uma visão meritocrática que estrutura a narrativa sobre a família:

\begin{abstract}
Meu pai era agrônomo, tinha um irmão agrônomo e uma irmã casada com agrônomo. A minha mãe era filha de um agrônomo e tinha três irmãos, os três eram agrônomos. Eu tenho uma irmã só, casada com agrônomo e tem dois filhos, os dois são agrônomos. Eu tenho quatro filhos. Os dois homens são agrônomos e tenho uma nora agrônoma (...) O pai do meu pai era fazendeiro aqui em São Paulo. Quebrou em 29. (...) Aí ele entregou tudo para o banco do Brasil e foi morrer como lenhador no sul do Estado (...) Um homem riquíssimo. Não sabia o que era Nova Iorque, bolsa, crack. E o pai da minha mãe era um agrônomo italiano que fugiu da Europa, imigrou para o Brasil, saiu da Europa na miséria e veio tocar uma fazenda de café em São Paulo cujo dono quebrou em 29 e vendeu suas terras para os colonos italianos. Então, o pai da minha mãe que, era pobre, ficou fazendeiro pela mesma razão que o pai do meu pai que era fazendeiro ficou pobre. O meu pai, que era agrônomo, casou com a minha mãe, virou fazendeiro de novo e eu virei Ministro da Agricultura. Esta é a mobilidade social do Brasil. $^{7}$
\end{abstract}

Portanto, Roberto Rodrigues valoriza a trajetória da família como um retrato exemplar da mobilidade social no Brasil. Ao mesmo tempo em que revela a reprodução social da família no campo da agricultura e da agronomia, valoriza um olhar meritocrático próprio da lógica liberal na gestão dos negócios, ao ressaltar o processo de falência de seu avô paterno e a recuperação econômica de seu pai. Além disso, quando justifica a perda dos negócios do avô paterno pelo seu

\footnotetext{
6 Entrevista Roberto Rodrigues http://www.jcmaschietto.com.br/index.php?link=entrevistas\&sublink=entrevista 1. Acesso 23.julho.2017.

7 Entrevista Roberto Rodrigues http://www.jcmaschietto.com.br/index.php?link=entrevistas\&sublink=entrevista 1. Acesso 23.julho.2017.
} 
desconhecimento do mercado financeiro durante a grande crise de 1929, valoriza, assim como quando destaca a formação predominante de agrônomos na família, um olhar mais técnico e empresarial sobre a gestão dos interesses familiares. Enquanto conferem grande destaque à "tradição" familiar na agricultura, os Rodrigues constroem a sua auto-imagem como representantes por excelência da vanguarda empresarial no campo brasileiro.

Assim, podemos concluir que a família de Roberto Rodrigues apresenta uma profunda relação entre negócios e família, imprimindo a marca da gestão e da administração como um elemento que estrutura a trajetória dos Rodrigues e a sua própria ideia de "agricultura familiar". Discorrendo acerca da forma com que o patronato rural percebe a estrutura social no campo, Bruno (2016) ressalta a estratégia de apagamento da desigualdade social por meio do desconhecimento da diferença entre pequenos e grandes produtores/proprietários. Nesta operação é possível perceber que, embora representante de uma agricultura técnica e produtivamente muito moderna, Roberto Rodrigues ainda se passa no plano discursivo como "agricultura familiar". Neste sentido, a autora destaca a seguinte fala de Rodrigues:

Eu sou agricultura familiar. Eu tenho 1.200 hectares, meus dois filhos tocam e nós temos 150 empregados. A agricultura familiar não quer dizer um conceito para a pequena propriedade. É a empresa-família. Na Inglaterra, o conceito é muito claro: você tem uma empresa de 600 hectares tocada pela família. Tem 150 empregados, mas é a família que toca. Aliás, pequena, grande, média, mínima, isso é coisa da Idade da Pedra, só interessa para o banco dizer para quem não vai dar crédito. Acabou! (Apud BRUNO_RODRIGUES, 1997).

Deste modo, Roberto Rodrigues, apesar de defender uma administração empresarial e profissionalizada também se reivindica família. Para ser da "agricultura familiar" não importam as diferenças patrimoniais, mas principalmente se o núcleo da atividade econômica é a família e qual sua relação com a agricultura. Neste sentido é possível observar a presença constante da ambivalência entre a racionalidade empresarial moderna da família Rodrigues e a tradição expressa na sua trajetória política e econômica.

\section{Katia Abreu e a defesa da tradição familiar}

Diferentemente dos Rodrigues a família de Kátia Abreu não possuía vínculo histórico com a atividade agropecuária e tampouco eram proprietários de terras. Naturais de Goiânia, a família era composta por profissionais de diferentes áreas: a mãe era professora primaria, o pai profissional liberal e o irmão funcionário público. Nascida em 1962, Kátia Abreu foi a única mulher em uma família de oito irmãos, tendo se formado em psicologia na Universidade Católica de Goiás- UCG. 
Dessa maneira, sua trajetória como produtora rural se iniciou posteriormente, ao se casar com um pecuarista do Tocantins, Irajá Silvestre. No casamento teve três filhos, no entanto, durante a terceira gravidez, em 1987, seu esposo faleceu em um acidente aéreo, deixando ela no encargo das propriedades da família. A partir daí, além de dirigir os negócios herdados, Kátia Abreu logrou se constituir como representante de classe, elegendo-se para o Senado Federal como importante liderança da agropecuária.

Ao nos debruçarmos sobre a concepção de família de Katia Abreu, encontramos com muita força a presença da questão de gênero na forma em que as relações familiares aparecem em suas falas. Assim, dois aspectos merecem ser destacados. De um lado, na narrativa sobre suas origens como produtora rural e representante patronal, Katia Abreu valoriza sua condição de viúva e mulher independente, que assumiu os negócios da família de forma bem sucedida alcançando uma posição de destaque na militância classista e na política institucional. Neste sentido, sua trajetória carrega consigo o signo de primeira mulher presidente da Confederação Nacional da Agricultura e Pecuária (CNA), Senadora pelo estado do Tocantins e Ministra da Agricultura, Pecuária e Abrastecimento. De outro lado, contudo, o que parece predominar em seus discursos são relações familiares de ordem mais tradicionais e patriarcais, pois, além de construir suas alianças políticas e redes de apoio com base em tradicionais mecanismos de articulação entre famílias políticas, a representante do patronato rural recorre com frequência à condição de mãe zelosa e imaculada para legitimar-se politicamente.

Katia Abreu relata que em sua primeira ida à fazenda já como viúva, ao abrir o cofre encontrou uma espécie de dossiê deixado pelo marido no qual constava um plano de investimentos da fazenda, a gestão dos negócios futuros, a ordem de pagamentos prioritários e a gestão da própria família.

\footnotetext{
"Foi quando iniciei minha vida pública e me tornei chefe de família por uma tragédia pessoal. Com a morte do meu marido, há 20 anos, tive de assumir o comando dos negócios da família e me tornei produtora rural, à época com 25 anos", informa.
}

Segundo ela, sua família tinha por certo que ela venderia as terras e voltaria a Goiânia, para abrir uma loja ou então trabalhar como psicóloga. No período que assumiu a fazenda, descreve que foi de grande esforço para compreender o funcionamento da atividade. No entanto, ressalta que, mesmo grávida, para "observar mais de perto os trabalhos nas terras", aceitou o conselho de um funcionário da fazenda e aprendeu a pilotar tratores ${ }^{8}$. Parte deste esforço no cuidado com a fazenda

\footnotetext{
${ }^{8}$ Entrevista concedida ao entrevistador Kenedy Alencar disponível em: https://www.youtube.com/watch?v=6CBoWJ0jo4; . Acesso 23.julho.2017.
} 
aparece frequentemente em suas falas, ao recordar que não queria que sua fazenda fosse conhecida ou tivesse aparência de "fazenda de viúva", algo visto pejorativamente por ela e pelos demais fazendeiros da região.

Deste modo, Kátia Abreu conseguiu permanecer na atividade do marido e ampliar seus negócios, comprando mais terras. Segundo ela, com seu trabalho foi possível duplicar a herança recebida, ampliando as atividades produtivas para além da pecuária com a introdução da sojicultura e do cultivo de eucalipto.

Uma vez dominada a administração das propriedades herdadas, a "viúva do Irajá", como fícou conhecida no início, também passou a participar da militância política classista movida pelos fazendeiros vizinhos, afiliando-se ao Sindicato Rural de Gurupi. Assim, seis anos após a morte de seu marido, Katia Abreu concorreu à presidência da associação. "Fui eleita presidente do sindicato rural, em eleição duríssima. Enfrentei machismo, violência. Venci. Depois, é o que se sabe: ruralismo e política"10, diz.

Katia Abreu valoriza sua trajetória na grande política institucional como representante patronal através da ocupação de postos parlamentares e, finalmente, como Ministra da Agricultura no segundo governo Dilma Roussef. Em 1998 candidatou-se, pela primeira vez, a deputada federal se elegendo como suplente. Em 2002 foi eleita para o mesmo cargo como a mais votada do estado, assumindo nesta legislatura a condição de presidente Frente Parlamentar da Agricultura (FPA) mais conhecida como Bancada Ruralista, no Congresso Nacional. A partir de então se consolidou como liderança nacional, elegendo-se para o Senado na eleição seguinte - cargo para o qual se reelegeu nos pleitos posteriores.

Com relação à representação corporativa em 1995 Katia Abreu foi eleita presidente da Federação da Agricultura do Estado do Tocantins (FAET), onde ficou por quatro mandatos consecutivos ${ }^{11}$.Em 2008, se elegendo a primeira mulher presidenta da CNA, onde permaneceu até 2011.

Os papeis sociais ligados à sua condição de mulher e a questão de gênero aparecem como central na construção de representante política: mulher, viúva, mãe de dois filhos que foi capaz de gerir de forma profissional os seus próprios negócios, superando a condição de "viúva", se tornando

\footnotetext{
${ }^{9}$ Expressão que denota uma fazenda malcuidada, geralmente atribuída ao fato da mulher não conseguir manter a qualidade na gestão de uma fazenda assim como os homens conseguem. Kátia, inclusive, vangloria-se de seus feitos e relata que não permite que uma cerca esteja em más condições e nem que sua sede e seus animais aparentem problemas.

${ }^{10}$ Disponível em: http://sistemafaeg.com.br/noticias/4370-a-primeira-senhora-do-campo. Acesso 23.julho.2017.

${ }^{11}$ Disponível em http://faetrural.com.br/pagina-faet.html. Acesso 01.junho.2016.
} 
a primeira grande liderança política feminina do patronato rural, um campo marcadamente conservador, e ganhando lugar entre os grandes da cena política nacional. Embora esta dimensão de empoderamento feminino da trajetória de Kátia Abreu sugira efetivamente uma abordagem mais progressista, dita moderna, das condições de mãe, esposa, viúva, chama a atenção como que, ao mesmo tempo, estas mesmas categorias são utilizadas em práticas de construção de suas alianças políticas e em alguns discursos proferidos no parlamento.

Em relação às alianças políticas, destaca-se o caso em que se realizou a nomeação de seu filho, Irajá Abreu, para o secretariado do governador do Tocantins Siqueira Campos como uma forma de selar o compromisso entre as duas famílias. As campanhas de ambos eram "apadrinhadas" uns pelos outros, especialmente no processo das primeiras eleições à Câmara Federal de Kátia Abreu. Até que um conflito entre as famílias se instaurasse em razão de divergências entre ela e Siqueira Campos as famílias mantiveram um importante pacto político no Tocantins. Além disso, Katia Abreu incentivou as candidaturas de seus filhos, tendo Irajá Abreu sido eleito deputado federal pelo Tocantins e Iratã Abreu, o mais novo, vereador da cidade de Palmas (TO). Atualmente Iratã, apesar de ter abandonado a carreira política, tem se dedicado a administrar os negócios da família. Destaca-se também a permanência de Irajá Abreu no Partido Social Democrático (PSD) mesmo depois da migração partidária de sua mãe. Segundo a Senadora do Partido do Movimento Democrático Brasileiro (PMDB) a permanecia dele no PSD foi "bem pensado por eles".

Além disso, outro traço da concepção tradicional de família de Katia Abreu é a figura da "mãe zelosa". Em discurso no Senado Federal a respeito do trabalho escravo, ela afirma que como mãe não pode ser favorável a trabalho escravo, em outras palavras, seria incapaz de fazer mal aos trabalhadores e de pregar jornadas exaustivas de trabalho a seus funcionários. A representação de mãe tida por ela é aquela vista como sem mácula, associada a uma noção de pureza no pensar e agir, portanto, uma mãe seria incapaz de fazer mal a outrem.

Em defesa do irmão, acusado de ser proprietário de uma fazenda em que foram encontrados trabalhadores em situação análoga à escravidão ela rebate: "sou temente a Deus e mãe de família sei que a justiça de Deus é maior”. Família e fé cristã se confundem em suas argumentações. Discutindo o que seria um trabalho degradante ou exaustivo afirma em 2013:

\footnotetext{
"Eu quero aqui deixar bastante claro que ninguém concorda com jornada exaustiva, que ninguém concorda com trabalho degradante, muito menos eu, que sou mulher, que sou mãe, que sou avó".
} 
Em 2007 quando se coloca a questionar no Senado uma ação do presidente Lula, Kátia Abreu compara a gestão do dinheiro público com a gestão financeira de uma casa provida pelo pai da família. Descrevendo a função do pai, diz: "precisa botar ordem financeira em sua família". Nota-se, portanto, uma leitura patriarcal na forma de fazer política, onde as noções de pai, presidente, patrão se confundem.

Dessa maneira, Katia Abreu, ainda que possuindo um perfil significativamente distinta do de Roberto Rodrigues, de forma similar apresenta ambivalências na sua visão predominante de família e na forma com que as relações de parentesco aparecem no seu discurso e trajetória. Sendo a primeira mulher presidente da CNA, ela não hesita em valorizar a sua condição de mulher para descrever sua trajetória e conquistas profissionais e políticas. Ao mesmo tempo, não rompe plenamente com a concepção predominantemente patriarcal de família. Muito pelo contrário, Katia Abreu recorre com grande insistência a referenciais tradicionais da condição de mãe e de pai, para fundamentar muitos de seus argumentos junto à sua base social.

\section{Considerações finais}

Para finalizar, gostaríamos de ressaltar que os dois perfis familiares não necessariamente aparecem em sua forma pura. Ao contrário, como é possível perceber, o modo com que os dois representantes do patronato rural acionam a família, apresenta nuances e pontos em comum, apesar de distintos. Neste sentido, a "família Roberto Rodrigues" ainda que defenda uma filosofia de gestão própria, sugerindo uma concepção moderna e empresarial de família predominante, reproduz nos processos de sucessão geracional prática associadas ao patriarcalismo de ordem mais tradicional. Assim, legando aos filhos homens e primogênitos a primazia e o protagonismo sobre a gestão dos negócios familiares, a família Roberto Rodrigues também apresenta traços mais tradicionalistas. No caso da "família Kátia Abreu", embora predominantemente de caráter tradicional, em alguns momentos se diferencia destes traços característicos ao questionar a condição de submissão por ser mulher, relativizando, assim, as concepções patriarcais presentes em suas falas.

Assim, pudemos constatar que, mesmo com significativas diferenças, ambos recorrem à instituição família como ferramenta de construção da sua representação política e forma de reprodução social. Seja atribuindo a família um sentido de gestão empresarial, seja recorrendo a referenciais clássicos das relações sociais do patriarcado, tanto a família Roberto Rodrigues como a 
família Kátia Abreu encontram nas relações familiares fontes fundamentais de legitimidade política e social.

\section{Referências}

BOURDIEU, Pierre. O poder simbólico. Rio de Janeiro/Lisboa: Bertrand Brasil/Difel, 1989.

BOURDIEU, Pierre. Razões Práticas. Sobre a teoria da ação. Campinas, São Paulo: Papirus, 2011.

BRUNO, Regina. Desigualdade, agronegócio, agricultura familiar no Brasil. Estudos Sociedade e Agricultura, abril de 2016, vol. 24, n. 1, p. 142-160, ISSN 1413-0580.

. Um Brasil Ambivalente: agronegócio, ruralismo e relações de poder. Rio de Janeiro: Mauad X; Seropédica, RJ: EDUR, 2009.

BRUNO, Regina e PRADO, Fellipe. "Katia Abreu: representação política e estratégias discursivas". XVII Congresso da Sociedade Brasileira de Sociologia. Porto Alegre (RS), julho de 2015, 17 pp.

FERNANDES, Afonso Henrique de Menezes. A Frente Ampla da Agropecuária Brasileira: O patronato rural moderno na Constituinte de 1988. VII Encontro da Rede de Estudos Rurais, 2016.

MANNHEIM, Karl. O pensamento conservador. In: MARTINS, José de Souza (Org.). Introdução à Sociologia Rural. São Paulo, 1981.

MENDONÇA, Sonia Regina de. A Classe Dominante Agrária: natureza e comportamento (19641990). São Paulo, SP: Expressão Popular, 2010.

MARTINS, José de Souza O poder do atraso. Ensaios de sociologia da história lenta, (São Paulo: Hucitec, 1994.

PRADO, Fellipe Silva. Hegemonia do Agronegócio e Representação Patronal: Kátia Abreu fusão de liderança política e corporativa? Seminário CPDA 40 anos, 2016.

WEBER, Max. Economia e Sociedade. Fundamentos da Sociologia Compreensiva. Brasília: Editora Unb Vol. 1 e 2. 2003.

\section{Fontes:}

Entrevista Roberto Rodrigues:

http://www.jcmaschietto.com.br/index.php?link=entrevistas\&sublink=entrevista_1

Entrevista Paulo Rodrigues:

http://cpdoc.fgv.br/agronegocio/paulo-rodrigues

Falas de Plenário no Senador Federal - Katia Abreu:

http://www25.senado.leg.br/web/senadores/senador/-/perfil/1249

Biografia Oficial Katia Abreu:

http://senadorakatiaabreu.com.br/biografia/ 